\title{
Aplicação do Óleo Essencial de Pimenta Dioica Lindl. como Moluscicida Frente ao Caramujo Transmissor da Esquistossomose.
}

\author{
Gustavo O. Everton, Amanda M. Teles, Adenilde N. Mouchrek, \\ Victor E. M. Filho
}

Extraído quantitativamente o óleo essencial por destilação a vapor. O óleo essencial obtido LC50 de 39,81 $( \pm 0,17)$. Os resultados indicam que o óleo essencial avaliado é composto de substâncias que fornecem atividade contra moluscicida no combate ao caracol transmissor esquistossomose.

Palavras Chave: Óleo; Caramujo; Moluscicida.

Extracted quantitatively the essential oil for hydrodistillation. The essential oil obtained LC50 of $39.81( \pm 0.17)$. The results indicate that the rated essential oil is composed of substances that provide activity against molluscicide in combating schistosomiasis transmitter snail.

Keywords: Oil; Snail; Molluscicide. 


\section{Introdução}

A esquistossomose, conhecida como barriga d'água, xistosa, doença do caramujo, xistosomose transmitida por caramujo, da espécie Biomphalaria glabrata․ No Brasil, a doença foi descrita em 18 estados e no Distrito Federal, sendo sua ocorrência diretamente ligada à presença dos moluscos transmissores ${ }^{2}$.

As substâncias moluscicidas são empregadas para o extermínio de moluscos e utilizadas para controlar caramujos vetores de parasitas. Moluscicidas sintéticos têm sido utilizados em programas de controle de doenças veiculadas por caramujos. Enfatiza-se que mais de 7.000 produtos químicos já foram testados com esta finalidade, mas poucos merecem destaque. Dentro desses, pode-se citar: sulfato de cobre, Gramaxone, hidróxido de cálcio, N-tritilmorfolina (Frescon), niclosamida (Bayluscid), carbamato, metaldeido, organofosfato ${ }^{3}$.

O moluscicida sintético niclosamida é o único recomendado para combater caramujos vetores de doenças4. Contudo, o uso de moluscicida sintético tem gerado preocupação em relação a fatores como: toxicidade para outras espécies, devido à sua baixa seletividade; contaminação do meio ambiente ${ }^{3}$ e resistência de caramujos da espécie B. glabrata ${ }^{5}$. Nesse contexto, a procura de substâncias facilmente biodegradáveis tem aumentado o interesse pelo uso de moluscicidas de origem vegetal. Os compostos de origem vegetal com potencial moluscicida têm sido amplamente utilizados na literatura ${ }^{6}$.

A Organização Mundial da Saúde enfatiza a necessidade de estudos moluscidas de plantas com a finalidade de tornas menos oneroso e mais eficiente o controle da esquistossomose.

O controle da esquistossomose demanda medidas que englobam tratamento de portadores, saneamento básico, educação sanitária e aplicação de moluscicidas. A presença de esquistossomose é indicador de condições precárias e este enfoque deve estar presente na mente de todos os especialistas no trabalho de controle desta endemia.

Diante dos argumentos anteriores, os óleos essenciais extraídos de plantas representam uma alternativa no controle do caramujo transmissor da esquistossomose, a fim de quebrar o ciclo evolutivo, antes que este venha contaminar o hospedeiro definitivo. Isto leva os estudiosos a pesquisarem substâncias oriundas de vegetais que pudessem contribuir na eliminação dos mesmos eficientemente.

A planta em estudo deve ser abundante em áreas endêmicas da doença, ou serem facilmente cultiváveis, o produto ativo responsável pela toxidez deve estar presente em partes de fácil regeneração da planta, como folhas, flores, frutos e sementes. O princípio ativo deve ser extraído preferencialmente com água, o extrato deve manter-se ativo sob quaisquer alterações físicas e químicas ${ }^{7,8}$.

Dessa forma, este estudo, teve por objetivo avaliar a toxicidade e a atividade moluscicida do óleo essencial extraído da folha de Pimenta dioica Lindl, espécie de grande importância medicinal e encontradas onde a doença é endêmica no Brasil.

\section{Metodologia}

O presente trabalho foi desenvolvido no Laboratório de Físico-Química do Pavilhão Tecnológico, Núcleo de Imunologia Básica e Aplicada (NIBA) da Universidade Federal do Maranhão (UFMA), Central Analítica da Universidade de Campinas, Central Analítica da UFMA, Núcleo de Combustível, Catálise e Ambiental (NCCA). Realizou-se o teste de atividade larvicida calculando-se a CL50 segundo o método Reed- Muench ${ }^{9}$.

\section{OBTENÇÃO DO ÓLEO ESSENCIAL}

As folhas foram coletadas na Cooperativa Agrícola Mista do Projeto Onça LTDA, no município de TaperoáBA, Brasil, em janeiro de 2017, registrada nos arquivos botânicos do Instituto Biodinâmico (IBD) de Botucatu de acordo com certificado no CA021205 e transportadas para o Laboratório de Físico-Química de Alimentos do Pavilhão Tecnológico da Universidade Federal do Maranhão (UFMA), onde foram secas em temperatura ambiente, trituradas (em pó) e armazenadas para extração do óleo essencial. 
Para extração do óleo essencial de Pimenta dioica Lindl., utilizou-se um extrator de Clevenger, de vidro acoplado a um balão de fundo redondo de $1000 \mathrm{~mL}$ acondicionado em manta elétrica como fonte geradora de calor. A cada rotina de extração do óleo essencial foram pesadas $30 \mathrm{~g}$ das folhas e adicionou-se agua destilada na proporção de 1:10 e colocadas em um balão de fundo redondo acoplado ao sistema extrator. A hidrodestilação foi conduzida a $100^{\circ} \mathrm{C}$ por $5 \mathrm{~h}$ recolhendo-se o óleo essencial extraído. O óleo foi seco por meio de percloração com Na2SO4. Essas operações foram realizadas em triplicatas e as amostras armazenadas em ampolas de vidro âmbar sob refrigeração de $4^{\circ} \mathrm{C}$ para evitar possíveis perdas de constituintes voláteis. Posteriormente submetido as análises.

O rendimento do óleo essencial foi expresso em porcentagem na relação massa/volume pela medida de densidade. Para realização dessa medida, foi utilizado um picnômetro de 1,0 $\mathrm{mL}$, previamente seco, tarado e aferido, onde se adicionaram as amostras a $25^{\circ} \mathrm{C}$, pesando-as em seguida. Após essa etapa, observou-se o volume $(\mathrm{mL}) \mathrm{de}$ óleo essencial obtido após a extração do óleo por massa (g) de material vegetal, conforme a fórmula descrita pela quarta edição da Farmacopeia Brasileira10 e por Fabrowski ${ }^{11}$.

\section{OBTENÇÃO E CULTIVO DOS CARAMUJOS}

As amostras dos caramujos da espécie Biomphalaria glabrata foram capturados nos períodos chuvosos de setembro/2016 a abril/2017, nas áreas com baixo saneamento no bairro Sá Viana, São Luís-MA, A técnica de coleta foi realizada de acordo com proposta de Brasil (2007), efetuando uma varredura com uma concha nas áreas submersas e os caramujos capturados foram recolhidos em um recipiente de vidro com tampa, com água do próprio criadouro. A busca dos mesmos foi realizada em diversos pontos de cada criadouro, a fim de obter uma amostragem significativa e depois transportados para o NIBA (Núcleo de Imunologia Básica e Aplicada) da UFMA, para posteriores análises.

Os caramujos foram mantidos em laboratório por 30 dias sendo analisados a cada 07 dias, para confirmação da ausência de infecção por Schistossoma mansoni. Para isso, foram colocados 05 caramujos em recipientes de vidro transparente com $25 \mathrm{~mL}$ de água desclorada, ou seja, $5 \mathrm{~mL} /$ caramujo, exposto à luz (lâmpadas de $60 \mathrm{~W}$ ) por uma hora com uma distância de $30 \mathrm{~cm}$ para estimular a liberação das cercarias ${ }^{12}$ e levados para serem analisados, através de visualização com auxílio de uma lupa estereoscópica (8x), aqueles que estavam parasitados (positivos) eram etiquetados e separados para futura análise individual e os que não apresentaram sinais de infecção pelo trematódeo no período de 30 dias foram selecionados para o teste de atividade moluscicida.

\section{TESTE PARA ATIVIDADE MOLUSCICIDA}

Para a avaliação da atividade moluscicida foi utilizada à técnica preconizada pela Organização Mundial de Saúde8, onde dois testes foram efetuados em triplicata. No primeiro, denominado de teste piloto, preparou-se uma solução do óleo em estudo num volume de 500 $\mathrm{mL}$ na concentração de $100 \mathrm{mg} \mathrm{L}^{-1}$ e $0,15 \mathrm{~mL}$ de Tween 80 (tenso ativo), onde foram colocados 10 caramujos adultos, negativos para Schistossoma mansoni, obtendose no final uma proporção de $50 \mathrm{~mL} /$ caramujo e alimentando-os com alface hidropônico ad. libittum ${ }^{13}$. Os mesmos ficaram expostos na solução por $24 \mathrm{~h}$, sob temperatura ambiente, removidos da solução, lavados por duas vezes com água desclorada, colocados em um recipiente de vidro contendo $500 \mathrm{~mL}$ de água desclorada, alimentando-os com alface hidropônico e observados a cada $24 \mathrm{~h}$, por 4 dias para avaliar a mortalidade.

No segundo teste, denominado de concentração letal (CL50), foram preparadas soluções de cada óleo num volume de $500 \mathrm{~mL}$ nas concentrações $10,25,50$ e $75 \mathrm{mg} \mathrm{L}^{-1}$ e $0,15 \mathrm{~mL}$ de Tween 80 (tensoativo), utilizando-se a mesma metodologia do teste piloto.

Para o controle negativo, utilizou-se também dois testes, no primeiro colocou-se $500 \mathrm{~mL}$ de água desclorada e 10 caramujos em um recipiente de vidro e no segundo 10 caramujos imersos em uma solução com $0,15 \mathrm{~mL}$ de Tween 80 em $500 \mathrm{~mL}$ de água destilada, alimentando ambos com alface hidropônico e procedendo-se a análise igualmente realizada nos testes anteriores. 


\section{TESTE DE TOXICIDADE}

Para a avaliação da letalidade de Artemia salina Leach, foi preparada uma solução salina estoque de cada óleo essencial na concentração de $10.000 \mathrm{mg} \cdot \mathrm{L}^{-1}$ e $0,02 \mathrm{mg}$ de Tween 80 (tenso ativo). Alíquotas de 5, 50 e $500 \mu \mathrm{L}$ desta foram transferidas para recipientes e completados com solução salina já preparadas anteriormente até $5 \mathrm{~mL}$, obtendo-se no final concentrações de 10, 100 e 1000 mg.L1, respectivamente. Todos os ensaios foram realizados em triplicatas, onde dez larvas na fase náuplio foram transferidas para cada um dos recipientes. Para o controle do branco utilizou-se $5 \mathrm{~mL}$ da solução salina e para o controle negativo $5 \mathrm{~mL}$ de uma solução $4 \mathrm{mg} . \mathrm{L}^{-1}$ de Tween 80 . Após 24 horas de exposição, realizou-se a contagem das larvas vivas, considerando-se mortas aquelas que não se movimentaram durante a observação e nem com a leve agitação do frasco.

Adotou-se o critério estabelecido por Dolabela14 para classificação da toxicidade dos óleos essenciais, sendo considerado produto altamente tóxico quando CL50 $\leq 80 \mathrm{mg}$. $\mathrm{L}^{-1}$, moderadamente tóxico para $80 \mathrm{mg}$. $\mathrm{L}^{-1} \leq \mathrm{CL} 50 \geq 250 \mathrm{mg}$. $\mathrm{L}^{-1} \mathrm{e}$ levemente tóxico ou atóxico quando CL50 $250 \mathrm{mg} . \mathrm{L}^{-1}$.

\section{Resultados e Discussão}

Avaliação dos parâmetros físico-químicos do óleo essencial. Os parâmetros físico-químicos dos óleos essenciais são importantes não apenas para determinação da qualidade, como também para o controle da sua pureza. Os resultados são apresentados na Tabela 1 .

Tabela 1. Parâmetros físico-químicos do óleo essencial estudado.

\begin{tabular}{|l|l|}
\hline \multicolumn{2}{|c|}{\begin{tabular}{c|} 
Parâmetros Físico-químicos \\
Oreo essencial Pimenta dioica Lindl
\end{tabular}} \\
\hline Densidade $(\mathrm{g} / \mathrm{mL})$ & 0,982 \\
\hline Índice de refração(ND $\left.25^{\circ}\right)$ & 1,5185 \\
\hline Solubilidade em álcool a $90 \%(\mathrm{v} / \mathrm{v})$ & $1: 2$ \\
\hline Cor & Amarelo \\
\hline Aparência & Límpido \\
\hline Rendimento $(\mathrm{m} / \mathrm{m})(\%)$ & 1,80 \\
\hline
\end{tabular}

Para os componentes do óleo extraído das folhas da Pimenta dioica Lindl, Mouchrek Filho15, Sobrinho ${ }^{17}$ e Carvalho $^{16}$, obtiveram os mesmos valores da densidade de $0,980 \mathrm{~g} / \mathrm{mL}$, um valor da densidade de $0,982 \mathrm{~g} \mathrm{~mL}^{-1}$. Para o índice de refração, Mouchrek Filho15 e Carvalho ${ }^{16}$ obtiveram os mesmos valores de $1,5^{15}$ e Sobrinho ${ }^{17}$ de 1,521. Para a solubilidade, Mouchrek Filho15, Sobrinho ${ }^{17} \mathrm{e}$ Carvalho ${ }^{16}$ encontraram valores semelhantes de 1:2 (álcool $70 \%)$.

Comparando os valores para o óleo essencial estudado com os da literatura, pode-se observar que houve uma similaridade entre eles, no que diz respeito aos parâmetros analisados. As pequenas diferenças nos valores encontrados podem ser atribuídas a fatores tais como época de coleta, diferentes tipos de solo, condições e tempo de armazenamento. Avaliação da Cinética de Extração do Óleo essencial de Pimenta dioica Lindl.

A extração do óleo essencial foi realizada num tempo de 05 horas, para uma massa de $30 \mathrm{~g}$ de amostra, com uma temperatura de $100^{\circ} \mathrm{C}$. Na figura 1 pode ser observado o tempo máximo.

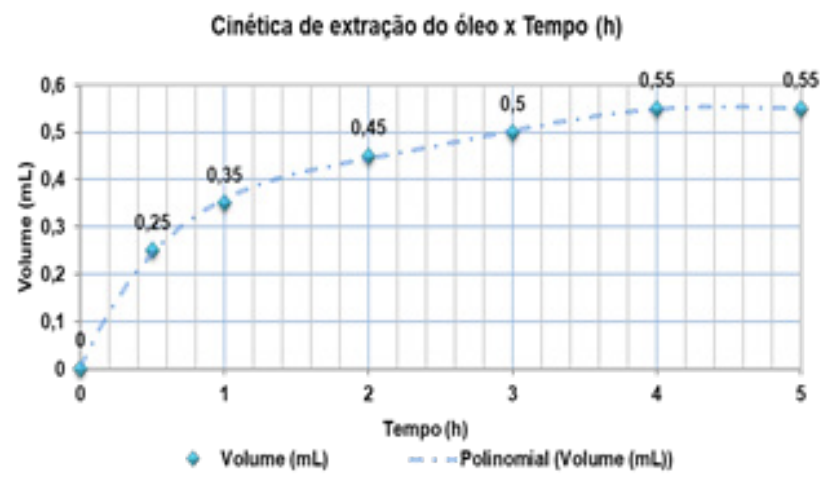

Figura 1. Cinética referente ao rendimento de extração do óleo em função do tempo, com massa de $30 \mathrm{~g}$ e temperatura de $100^{\circ} \mathrm{C}$.

De acordo com os resultados obtidos na extração, o tempo máximo e o volume para óleo extraído das folhas da Pimenta dioica Lindl foi de 4,0 horas e $0,55 \mathrm{~mL}$. 
Segundo Mouchrek Filho ${ }^{15}$, o tempo de extração do óleo essencial é um dos principais parâmetros físico-químicos da indústria de essências, no que se refere à qualidade e à natureza econômica. Por isso, uma destilação rápida pode conduzir a um produto contendo predominantemente constituintes mais voláteis, porém destituído das melhores características; ao contrário, uma extração prolongada encarece o produto e também pode sobrecarregá-lo de compostos de aromas indesejáveis ${ }^{18}$.

$\mathrm{O}$ rendimento $\mathrm{m} / \mathrm{v}$ foi calculado mediante a quantidade de óleo extraído, da massa e da densidade, para a Pimenta dioica Lindl foi de 1,80\%,

Ao extrair o óleo essencial do óleo da Pimenta dioica Lindl, Mouchrek Filho15 e Sobrinho ${ }^{17}$ obtiveram rendimentos semelhantes, respectivamente de 2,3\%, 2,5\% e 2,9\%. Conforme Özcan e Chalchat ${ }^{19}$, a variação sazonal e a localidade são fatores importantes para diferentes variedades de plantas com relação aos rendimentos de extração encontrados na literatura.

\section{AVALIAÇÃo DO TESTE PILOTO}

Neste estudo foi realizado um teste piloto com o óleo essencial, na concentração de $100 \mathrm{mg}$. $\mathrm{L}^{-1}$. Os percentuais de mortalidade pelo tempo de exposição e observação do óleo podem ser observados no gráfico da Figura 2.

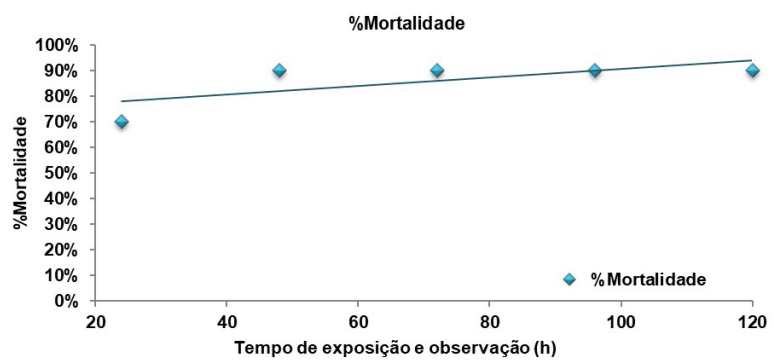

Figura 2. Percentual de mortalidade por tempo de exposição e observação para o teste piloto.

Inicialmente, foram realizados os testes pilotos na concentração de $100 \mathrm{mg} \mathrm{L}^{-1}$ para verificar se existe ou não atividade moluscicida do óleo. $\mathrm{O}$ estudo mostrou que a Pimenta dioica Lindl. foi de $90 \%$ em 48 horas também havendo hemorragia. Caracterizando que o óleo possuía componentes capazes de eliminar os caramujos adultos do gênero Biomphalaria glabrata.

\section{AVALIAÇÃO DA CONCENTRAÇÃO LETAL E ENSAIO DE TOXICIDADE}

Foram realizados testes nas concentrações de 75, 50, 25 e $10 \mathrm{mg} . \mathrm{L}^{-1}$, onde determinou-se a menor concentração letal.

Para avaliação da concentração letal do óleo essencial extraído da folha da Pimenta dioica Lindl pode-se observar no gráfico da Figura 3, os percentuais de mortalidade pela concentração.

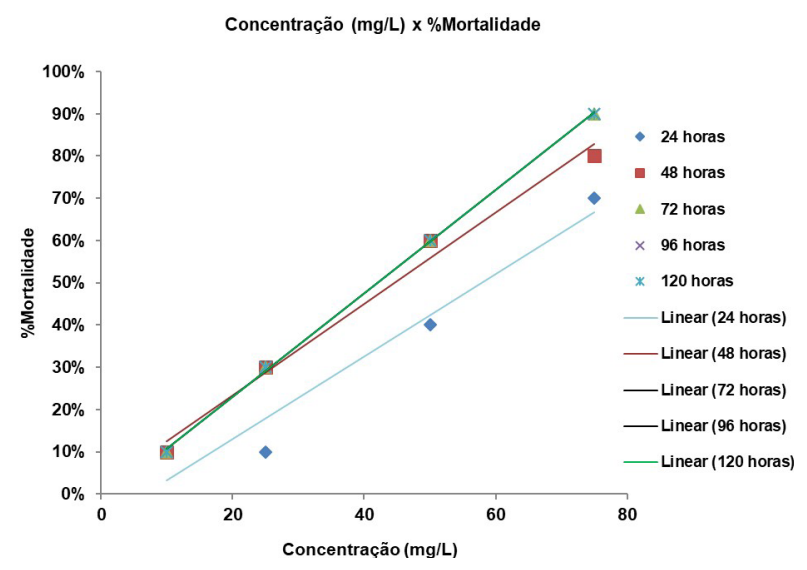

Figura 3. Percentual de mortalidade pelas concentrações do óleo essencial Pimenta dióica Lindl.

O gráfico mostra que os moluscos em 24, 48, 72, 96 e 120 horas de exposição na concentração de 75 mg.L-1 obteve uma mortalidade de 70, 80, 90, 90 e $90 \%$ respectivamente, para uma concentração de $50 \mathrm{mg} . \mathrm{L}-1$ foi de $40,60,60,60$ e $60 \%$, de 25 mg.L- 1 foi de $10,30,30,30$ e $30 \%$ e para 10 mg.L-1 foi de $10 \%$.

Para cada concentração os testes foram realizados em triplicata e os dados sobre o número de caramujos vivos e mortos foram encontrados através de uma média das três repetições para cada uma das cinco concentrações testadas (Tabela 2). 
Tabela 2. Mortalidade dos caramujos após testes em várias concentrações do óleo essencial extraído das folhas da Pimenta dioica Lindl.

\begin{tabular}{|c|c|c|c|c|c|c|}
\hline $\begin{array}{l}\text { Concentração } \\
\left(\mathrm{mg} . \mathrm{L}^{-1}\right)\end{array}$ & Log Concentração & Mortos & Vivos & $\begin{array}{c}\text { Acumulados } \\
\text { Vivos }\end{array}$ & $\begin{array}{c}\text { Acumulados } \\
\text { Mortos }\end{array}$ & $\%$ Mortalidade \\
\hline 100 & 2 & 9 & 1 & 1 & 28 & 90 \\
\hline 75 & 1,8751 & 9 & 1 & 2 & 19 & 90 \\
\hline 50 & 1,699 & 6 & 4 & 6 & 10 & 60 \\
\hline 25 & 1,398 & 3 & 7 & 13 & 4 & 30 \\
\hline 10 & 1 & 1 & 9 & 22 & 1 & 10 \\
\hline
\end{tabular}

A taxa de percentagem da mortalidade dos caramujos frente ao óleo da Pimenta dioica Lindl. é mostrada na Figura 4, tornando-se constante a partir do logaritmo da concentração 1,8751 (concentração $75 \mathrm{mg} \mathrm{L}^{-1}$ ). A Figura 5 mostra que a Concentração Letal 50\% (CL50), foi encontrada próxima ao Logaritmo da concentração 1,60; calculada através da intersecção das curvas de acumulados mortos e acumulados vivos, tendo como resultado a concentração de $39,81 \mathrm{mg} \mathrm{L}^{-1}$.

Para ser considerada moluscicida a substância deve eliminar o caramujo em todas as fases do seu ciclo de vida e no seu habitat natural, possuir baixas concentrações, baixo custo, ser estável no armazenamento em condições tropicais; fácil de transportar e aplicar; ter ação letal seletiva a caramujos, ser inócuo para o homem, animais domésticos, peixes e plantas, não sofrer decomposição na água e no solo e ser estável em condições de temperatura e irradiação solar8. Dessa forma, o óleo em estudo está dentro desses padrões sendo apresentado como agente moluscicida frente ao caramujo transmissor da esquistossomose.

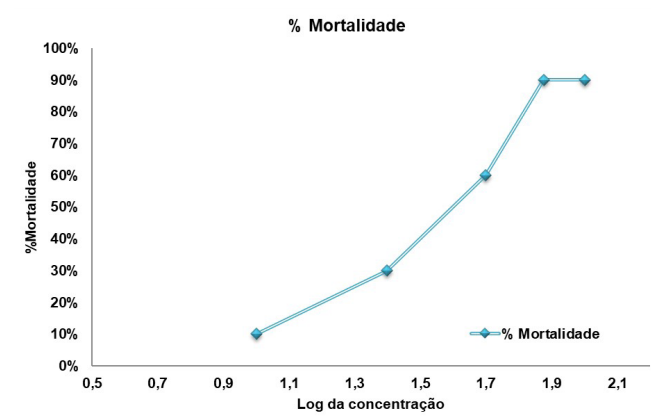

Figura 4. Taxa de mortalidade dos caramujos nas cinco concentrações diferentes do óleo essencial de Pimenta dioica Lindl.
A Organização Mundial de Saúde8 recomenda que, após a identificação de uma espécie com potencial moluscicida, sejam realizados estudos do perfil químico do vegetal, seguido da identificação da estrutura química responsável pela ação moluscicida, ensaios em campo, de estabilidade do composto e de toxicidade. Ensaios apresentados neste artigo.

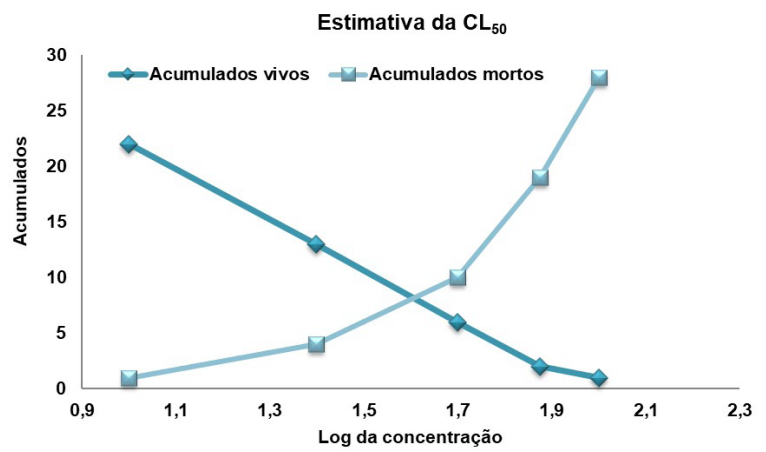

Figura 5. Estimativa da CL50 do óleo essencial de Pimenta dioica Lindl. pelo método Reed-Muench a partir do acumulado de caramujos vivos e mortos em função do logaritmo da concentração aplicada. A CL50 é o ponto de intersecção das duas curvas.

Para o ensaio de toxicidade, as culturas de Artemia salina foram incubadas a temperatura média de aproximadamente $28^{\circ} \mathrm{C}$, sendo feita a leitura do número de mortos após 24 horas. Foram consideradas larvas mortas todas que não apresentavam qualquer movimento ativo em cerca de vinte segundos de observação.

Para o óleo essencial extraído das folhas de Pimenta dioica Lindl a Tabela 3 mostra a média dos testes realizados em triplicatas. 
Tabela 3. Mortalidade das larvas após testes nas diferentes concentrações do óleo essencial extraído das folhas de Pimenta dioica Lindl.

\begin{tabular}{|c|c|c|c|c|c|c|}
\hline Concentração(mg. L-1) & Log Concentração & Mortos & Vivos & $\begin{array}{c}\text { Acumulados } \\
\text { Vivos }\end{array}$ & $\begin{array}{c}\text { Acumulados } \\
\text { Mortos }\end{array}$ & Mortalidade \\
\hline 1000 & 3 & 10 & 0 & 0 & 23 & 100 \\
\hline 100 & 2 & 8 & 2 & 2 & 13 & 80 \\
\hline 10 & 1 & 5 & 5 & 7 & 5 & 50 \\
\hline
\end{tabular}

De acordo com os resultados obtidos a Figura 6 mostra que a concentração Letal 50\% (CL50) do óleo essencial foi encontrada próxima ao logaritmo da concentração 1,15 , sendo calculada através da intersecção das curvas de acumulados mortos e vivos, tendo como resultado a concentração de $14,13 \mathrm{mg}$. $\mathrm{L}^{-1}$.

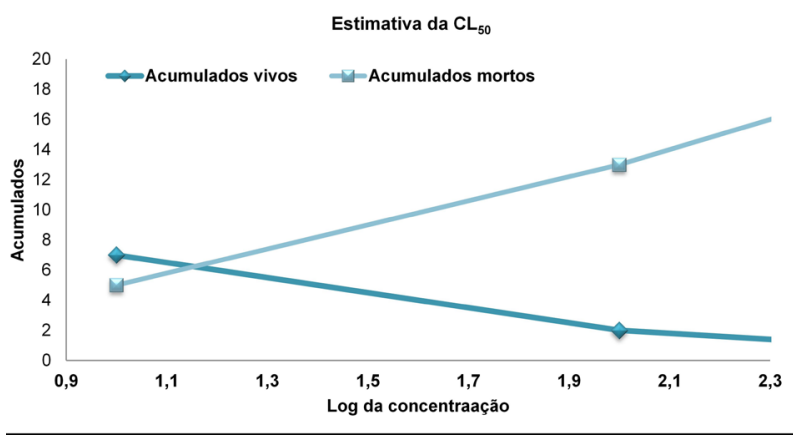

Figura 6. Estimativa da CL50 do óleo essencial da Pimenta dioica Lindl. pelo método Reed-Muench a partir do acumulado de larvas vivas e mortas em função do logaritmo da concentração aplicada. A CL50 é o ponto de intersecção das duas curvas.

Diversos trabalhos tentam correlacionar a toxicidade sobre Artemia salina com atividades como antifúngica, viruscida e antimicrobiana, parasiticida20, entre outras. McLaughlin ${ }^{7}$ e colaboradores têmutilizado sistematicamente este bioensaio na avaliação prévia de extratos de plantas conhecidas como antitumorais. As frações ou substâncias ativas são posteriormente testadas em diferentes culturas de células tumorais, obtendo-se uma boa correlação.

Pesquisadores utilizam sistematicamente este bioensaio na avaliação prévia de extratos de plantas conhecidas como antitumorais ${ }^{7}$, mostrando-se boa correlação para substâncias com CL50 < 103 mg. L ${ }^{-1}$. Neste caso, encontrase o óleo em estudo.

De acordo com os resultados obtidos verificou-se que as larvas da Artemia salina do grupo controle branco, somente com solução salina e controle negativo com solução salina e Tween 80 não houve mortalidade, permanecendo ativas.

Conforme Dolabela ${ }^{14}$, a avaliação da toxicidade do óleo essencial nas concentrações testadas, mostrou-se para o extraído das folhas de Pimenta dioica Lindl alta toxicidade aguda, indicando a importância do ensaio de toxicidade geral e a necessidade de maiores estudos para o óleo quando não obtiver bons resultados, para comprovar a segurança contra organismos não alvo nas regiões de ocorrência dos caramujos. Na literatura não foram encontrados estudos referentes à toxicidade de plantas deste gênero.

Por outro lado, uma baixa toxicidade pode ser considerada uma característica interessante para utilização de extratos vegetais em ambientes naturais para controle da população de caramujos. É relevante observar que a niclosamida, substância aprovada pela ANVISA-MS mostrou-se tóxica para espécies aquáticas como crustáceos do zooplancton ${ }^{21}$.

De acordo com os resultados obtidos nos estudos analíticos e na avaliação da toxicidade e atividade moluscicida do óleo essencial extraído da folha de Pimenta dioica Lindl, conclui-se que os parâmetros físico-químicos do óleo essencial estudado apresentaram valores semelhantes ao obtidos pela literatura. A atividade moluscicida do óleo revelou-se eficiente frente aos caramujos, sendo interessante e importante no controle e combate à esquistossomose. 


\section{Conclusões}

De acordo com os resultados obtidos nos estudos analíticos e na avaliação da toxicidade e atividade moluscicida do óleo essencial extraído da folha de Pimenta dioica Lindl, desenvolvido dentro do programa PIBIC cota 2017-2018 na Universidade Federal do Maranhão em parceria com outras instituições, conclui-se que os parâmetros físico-químicos dos óleos essenciais estudados apresentaram valores semelhantes ao obtidos pela literatura. A atividade moluscicida do óleo revelou-se eficiente frente aos caramujos, sendo interessante e importante no controle e combate à esquistossomose.

\section{Agradecimentos}

\section{Ao PCQA, ao CNPQ e à UFMA.}

\section{Referências Bibliográficas}

1. Raghavan,N. et al. Comparative gene analysis of Biomphalaria glabrata hemocytes pre-and post-exposure to miracidia of Schistosoma mansoni. Molécular\&Biochemical Parasitology, n.126, p.181-191, 2003.

2. Brasil. Guia de vigilância epidemiológica. 6. ed. Brasília: FUNASA, 2005. $816 \mathrm{p}$.

3. Cantanhede, S.P.D. et al. Atividade moluscicida de plantas: uma alternativa profilática. Revista Brasileira de Farmacognosia, v. 20 , n.2, p. 282-288, 2010.

4. Pinheiro, L. Cortez, D.A.G.; Vidotti, G.J.; Young, M.C.M.; Ferreira, A.G. 2003. Estudo fitoquímico e avaliação da atividade moluscicida de Kielmeyera variabilis MART. Química Nova 26: 157-160.

5. Gasparotto J.R. et al. Estudo fitoquímico e avaliação da atividade moluscicida do Calophyllum brasiliense camb (Clusiaceae). Química Nova, v. 28, n.4, p. 575- 578, 2005.

6. Amaral, R. S. \& Porto, M. A. S., 1994. Evolução e situação atual do controle da esquistossomose no Brasil. Revista da Sociedade Brasileira de Medicina Tropical, 27:73-90.

7. Mclaughlin, J. L.; Saizarbitori, T. C.; Anderson, J. E.; 1995. Tres bioensayos simples para quimicos de productos naturales. Rev Soc Venez Quim 18: 13-18.

8. World Health Organization (Who). Report of the Scientific working Group on Plant Molluscicide \& Guidelines for evaluation of plant molluscicides. Geneva: TDR/SC 4-SWE (4)/83.3, 1983.
9. Colegate, S.M.; Molyneux, R.J. Bioactive Natural Products: Detection, Isolation, an Structural Determination. Boca Raton: CRC, 1993.

10. Farmacopeia Brasileira Iv - PARTE 1. 4. ed. São Paulo: Editora Atheneu, 1996, 1.320p.

11. Fabrowski, F. J. R. T. Baker (Myrtaceae). Eucaliptus smithii como espécie produtora de óleo essencial no sul do Brasil. 2002, $225 \mathrm{f}$. Tese (Doutorado em Engenharia Florestal) - Centro de Ciências Agrárias, Universidade Federal do Paraná.

12. Smithers,S.R.\& Terry. The imunoly of Schistosomiasis. In: Souza, Nêuton da S. Visão Parasittológica da cepa humana de schistosoma mansoni em roedor silvestre. 1992. Monografia(Graduação em Farmácia)- Universidade Federal do Maranhão, São luis.

13. Malek, E. A. Snail Hosts of Schistomiasis and other Snail Transmitied Diseases in Tropical América.In: BARBOSA, F. S. Tópicos de Malacologia Médica-rio de janeiro: Fiocruz, 1995, p. 300-310

14. Dolabela, M.F. Triagem in vitro para a atividade antitumoral e anti- T.cruzi de extratos vegetais, produtos naturais e substâncias sintéticas. Belo Horizonte. Dissertação (Mestrado) - Universidade Federal de Minas Gerais, 1997. 128p

15. Mouchrek Filho, Victor Elias. Estudos Analíticos e modificações químicas por metilação e acetilação do eugenol contido no óleo essencial extraído das folhas da espécie Pimenta dioica Lindl. São Carlos. 2000, 124f. Tese (Doutorado em Química) - Universidade de São Paulo, Instituto de Química de São Carlos, São Carlos/SP, 2000.

16. CARVAlHO, L. M. Potencial de Manejo de Plantas Medicinais e Aromáticas na Agricultura. Aracajú-SE: EMBRAPA, 2006.

17. Sobrinho, João Reis Salgado. Estudo analítico do óleo essencial extraído das folhas da espécie Pimenta dioica Lindl. e sua aplicação como agente bactericida. (Mestrado em Química Analítica). Universidade Federal do Maranhão, São Luís, 2007.

18. Chaar, J. S. Estudos analíticos e modificação química por acetilação do linalol contido no óleo essencial da espécie Aniba duckei Kostermans. São Carlos, 2000, 150p. Tese (Doutorado) - Instituto de Química de São Carlos, Universidade de São Paulo.

19. Özcan, M.; Chalchat, J.C. Essential oil composition of Ocimum basilicum L. and Ocimum minimum L. in Turkey. Czech Journal of Food Sciences, v. 20, n. 6, p. 223-228, 2002.

20. Sahpaz, S.; Boris, Ch.; Loieau, P. M.; Cortes, D; Hacquemiller, R.; Laurens A.; Cavé, A.; Planta Medica. 1994, 60, 538.

21. Oliveira-Filho E. C.; Paumgartten F. J. R. 2000. Toxicity of Euphorbia milii latex and niclosamide to snails and nontarget aquatic species. Ecotox Environ Safe 46: 342-350. 


\section{Gustavo O. Everton*, Amanda M. Teles, Adenilde N. Mouchrek \& Victor E. M. Filho}

Universidade Federal do Maranhão, Departamento de Tecnologia Química, Laboratório de Pesquisa e Aplicação de Óleo Essenciais, CEP 65080-805, São Luís, MA, Brasil.

*E-mail: gustavooliveiraeverton@gmail.com 